\title{
EnaS: a new software for neural population analysis in large scale spiking networks
}

\author{
Hassan Nasser ${ }^{1 *}$, Selim Kraria ${ }^{2}$, Bruno Cessac ${ }^{1}$ \\ From Twenty Second Annual Computational Neuroscience Meeting: CNS*2013 \\ Paris, France. 13-18 July 2013
}

With the advent of new Multi-Electrode Arrays techniques (MEA), the simultaneous recording of the activity up to hundreds of neurons over a dense configuration supplies today a critical database to unravel the role of specific neural assemblies. Thus, the analysis of spike trains obtained from in vivo or in vitro experimental data requires suitable statistical models and computational tools.
The EnaS software [7], developed by our team, offers new computational methods of spike train statistics, based on Gibbs distributions (in its more general sense, including, but not limited, to the Maximal Entropy - MaxEnt) and taking into account time constraints in neural networks (such as memory effects). It also offers several statistical model choices, some of these models already used in the community (such GLM [6] and the conditional

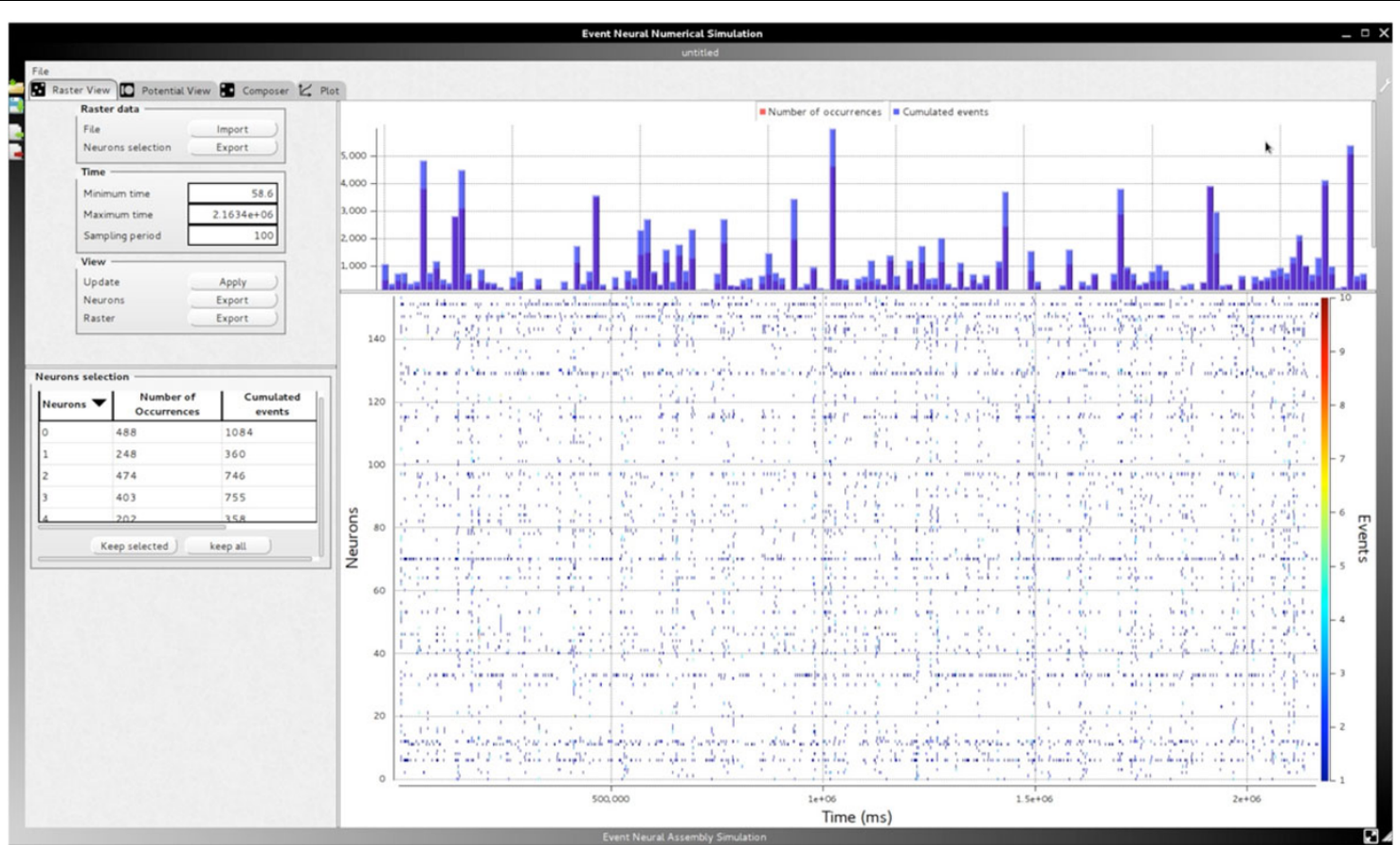

Figure 1 The GUI of EnaS. This page allows displaying a spike-train, showing the firing rates and configuring the binning value (sampling rate) of the data. It also allows selecting a subset of neurons and sorting the neurons with respect to their activity.

\footnotetext{
* Correspondence: hassan.nasser@inria.fr

'Neuromathcomp, INRIA/UNSA, Sophia-Antipolis, France

Full list of author information is available at the end of the article
} 
intensity models [5]), and some others developed by us ([1] and [2]), and allows a quantitative comparison between these models. It also offers a control of finite-size sampling effects inherent to empirical statistics.

EnaS allows large scale simulation thanks to our recent study [2] (hundreds of neurons) with spatio-temporal constraints. It's available as a Graphical User Interface in order to make the tools more accessible by non-programmers. Within EnaS framework, programmers are also allowed to implement new tools and integrate them with the existing modules. We featured EnaS with parallel processing on personal computers (using MPI) and on clusters (Using OpenMP).

\section{Author details}

${ }^{1}$ Neuromathcomp, INRIA/UNSA, Sophia-Antipolis, France. ${ }^{2}$ Dream, INRIA,

Sophia-Antipolis, France.

Published: 8 July 2013

\section{References}

1. Nasser H, Marre O, Cessac B: Spatio-temporal spike trains analysis for large scale networks using maximum entropy principle and Monte-Carlo method.[http://lanl.arxiv.org/abs/1209.3886].

2. Vasquez JC, Marre O, Palacio AD, Berry II MJ, Cessac B: Gibbs distribution analysis of temporal correlations structure in retina ganglion cells. Journal of Physiology 2012, 106(3-4):120-127.

3. Schneidman E, Berry MJ, Segev R, Bialek W: Weak pairwise correlations imply strongly correlated network states in a neural population. Nature 2006, 440(7087):1007-1012.

4. Pillow JW, Paninski L, Uzzell VJ, Simoncelli EP, Chichilnisky EJ: Prediction and decoding of retinal ganglion cell responses with a probabilistic spiking model. J Neurosci 2005, 25:11003-11013.

5. Ahmadian A, Pillow JW, Paninski L: Efficient Markov Chain Monte Carlo Methods for Decoding Neural Spike Trains. Neural Computation 2001, 23:46-96.

6. Event Neural Assembly Simulation. [http://enas.gforge.inria.fr].

doi:10.1186/1471-2202-14-S1-P57

Cite this article as: Nasser et al: EnaS: a new software for neural population analysis in large scale spiking networks. BMC Neuroscience 2013 14(Suppl 1):P57.

\section{Submit your next manuscript to BioMed Central} and take full advantage of:

- Convenient online submission

- Thorough peer review

- No space constraints or color figure charges

- Immediate publication on acceptance

- Inclusion in PubMed, CAS, Scopus and Google Scholar

- Research which is freely available for redistribution

Submit your manuscript at www.biomedcentral.com/submit 